\title{
Produtividade e componentes de rendimento de híbridos de milho em função da distribuição espacial na linha de semeadura
}

\author{
Felipe Castanho ${ }^{1}$, Smaylla El Kadri Ceccatto ${ }^{2}$, Esmael Lopes dos Santos ${ }^{3}$ \\ Centro Universitário Filadélfia (UNIFIL), Universidade Estadual de Londrina (UEL)², Centro Universitário Assis Gurgacz \\ $(\mathrm{FAG})^{3}$. E-mail: smayllaelkadri@hotmail.com
}

\begin{abstract}
Resumo
A uniformidade espacial na distância entre plantas na linha de semeadura e na época de emergência, é fundamental para alcançar altos tetos produtivos na cultura do milho. Objetivou-se avaliar a produtividade de dois híbridos de milho em função da distribuição espacial na linha de semeadura. O experimento foi conduzido no município Cambé-PR na segunda safra de milho em 2016. Foram avaliados os híbridos de milho Fórmula TL (Syngenta) e 2A401 Pw (Dow). O delineamento experimental utilizado foi em blocos ao acaso com quatro repetições. A unidade experimental foi constituída de quatro linhas de seis metros de comprimento e 0,70 $\mathrm{m}$ de espaçamento entre linhas. Foram realizados cinco tratamentos $(1 ; 2 ; 3 ; 4$ e 5 plantas agrupadas), caracterizados pela distribuição espacial na linha de semeadura. Os dados foram submetidos à análise de variância pelo teste $F$, com uso do software SISVAR e a comparação de médias foi realizada pelo teste de Tukey. Existe variabilidade genética para o rendimento de grãos quanto a distribuição de plantas na linha de semeadura. No componente plantas quebradas os dois híbridos estudados apresentaram porcentagem semelhantes, e diferenças mais acentuadas na variável plantas acamadas. O híbrido Fórmula foi capaz de compensar os espaços deixados pela desuniformidade na linha de semeadura.

Palavras-chave: densidade populacional; uniformidade espacial; Zea mays.
\end{abstract}

\section{Corn hybrids productivity depending in spatial distribution in the seeding line}

\begin{abstract}
Spatial uniformity in the distance between plants in the sowing line and at the time of emergence is essential to achieve high productive ceilings in the corn crop. The objective was to evaluate the productivity of two corn hybrids as a function of the spatial distribution in the sowing line. The experiment was carried out in the municipality of Cambé-PR in the second corn harvest in 2016. The hybrids of Formula TL (Syngenta) and 2A401 Pw (Dow) were evaluated. The experimental design used was in randomized blocks with four replications. The experimental unit consisted of four lines of six meters in length and $0.70 \mathrm{~m}$ of line spacing. Five treatments (1, 2, 3, 4 and 5 grouped plants) were performed, characterized by the spatial distribution in the sowing line. The data were subjected to analysis of variance by the $F$ test, using the SISVAR software and the comparison of means was performed by the Tukey test. There is genetic variability for grain yield in terms of plant distribution in the sowing line. In the broken plants component, the two hybrids studied presented similar percentages, and more pronounced differences in the variable bedded plants. The Formula hybrid was able to compensate for the spaces left by the unevenness in the seeding line.
\end{abstract}

Keywords: population density; spatial uniformity; Zea mays.

\section{Introdução}

O milho é uma cultura sensível a variações no arranjo de plantas e à competição intraespecífica devido à baixa capacidade de emissão de afilhos férteis, à limitada prolificidade 
e à insuficiente plasticidade foliar (ANDRADE; SADRAS, 2003; SANGOI et al., 2011).

A uniformidade espacial na distância entre plantas na linha de semeadura e na época de emergência, é fundamental para alcançar altos tetos produtivos na cultura do milho (SANGOI et al., 2012). O arranjo de plantas na lavoura pode ser alterado por mudanças na densidade, no espaçamento entrelinhas e na distribuição espacial e temporal das plantas na linha (SANGOI et al., 2010).

Variabilidade espacial na linha de semeadura são comuns na cultura do milho, em decorrência de classificação inadequada de sementes quanto ao formato, à massa e ao tamanho, a incompatibilidade entre o tamanho/formato da semente com os discos utilizados na semeadora, a regulagem inadequada da semeadora, a velocidade excessiva do trator e condições inadequadas de temperatura e umidade do solo durante a semeadura (SANGOI et al., 2010). Nestes casos, observam-se locais nas linhas de semeadura onde as plantas estão muito próximas entre si e a presença de espaços amplos sem presença de plantas (SANGOl et al., 2012).

A base para alta produção vegetal está relacionada com a disponibilidade $\mathrm{e}$ adequação de fatores extrínsecos à planta: disponibilidade de $\mathrm{CO}_{2}$, água, nutrientes $\mathrm{e}$ radiação e intrínsecos: ciclo de fixação de $\mathrm{CO}_{2}$, aparato fotossintético, arquitetura foliar e distribuição espacial de plantas. Segundo Junior (2008), as cultivares podem apresentar respostas diferenciadas quanto a produtividade em relação a distribuição espacial de plantas, além disso, algumas alterações importantes que ocorreram com o milho nas últimas décadas, tais como o aumento na densidade de plantas, a redução no espaçamento entre linhas e o incremento do potencial produtivo dos híbridos tornaram a produtividade da cultura mais sensível à desuniformidade na distribuição espacial.

Identificar a distribuição espacial adequada para cada cultivar é fundamental para alcançar bom rendimento de grãos e diante deste quadro, objetivou-se avaliar a produtividade de duas cultivares de milho em função da distribuição espacial na linha de semeadura.

\section{Material e métodos}

O experimento foi conduzido no município de Cambé-PR, conforme as seguintes coordenadas geográficas 2304' 42.84" de Latitude Sul e 511' 28.37" de Longitude Oeste e altitude média de $478 \mathrm{~m}$, sendo o clima da região classificado segundo Köppen do tipo $\mathrm{Cfa}$ (subtropical úmido). O solo da área é classificado como Latossolo Vermelho Distroférrico (SANTOS et al., 2013). Os dados climáticos durante a condução do experimento são apresentados na Figura 1.

Figura 1. Precipitação pluvial e temperatura média do ar, durante o ciclo de desenvolvimento da cultura do milho. Londrina, PR.

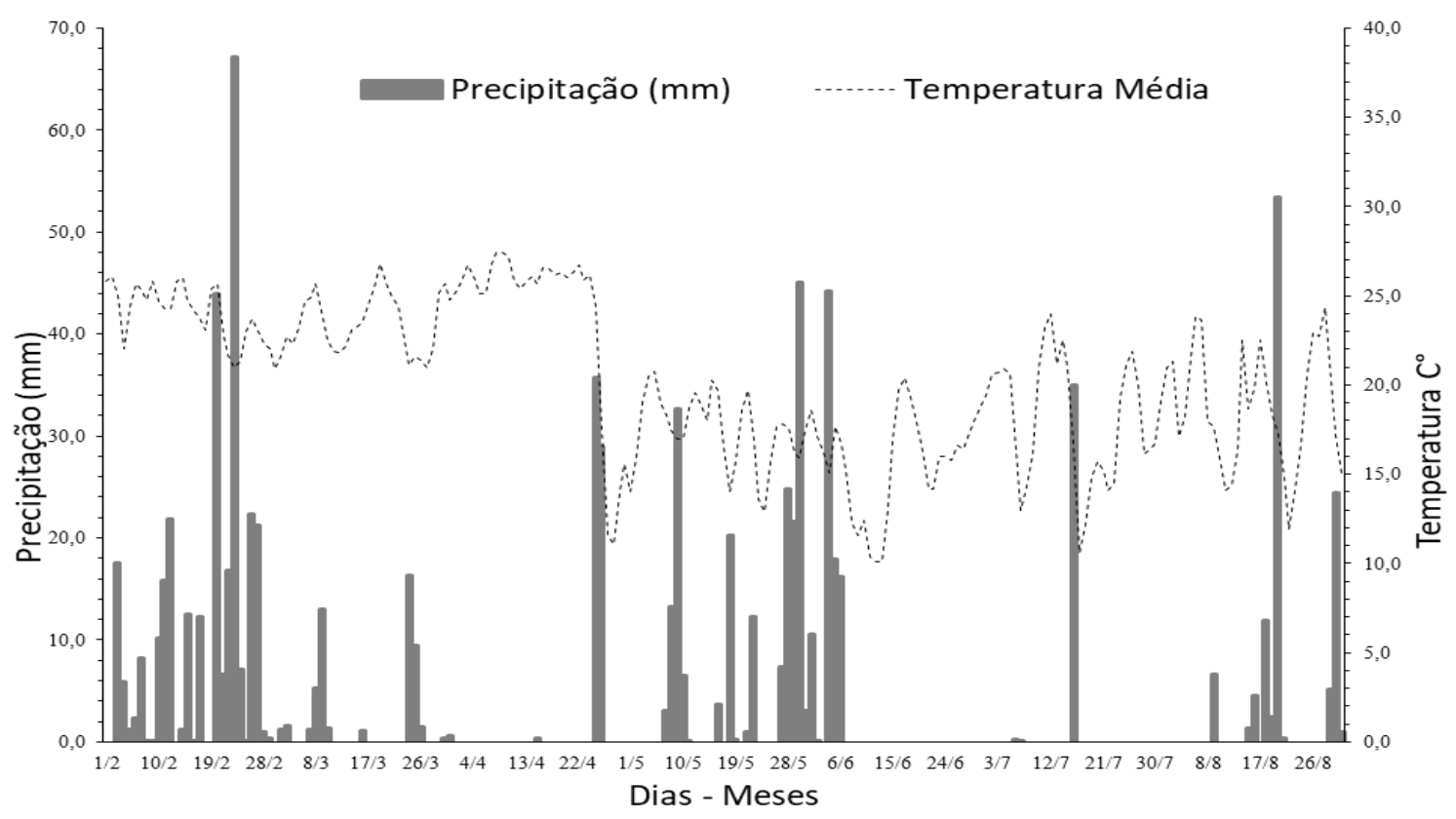


O delineamento experimental utilizado foi de blocos completos casualizados, com quatro repetições e esquema fatorial $2 \times 5$. O primeiro fator foi constituído por dois híbridos: Fórmula TL (Syngenta) e 2A401 Pw (Dow), ambos com tratamento de sementes industrial com Cruiser ${ }^{\circledR} 350$ FS e Maxim XL) e o segundo por cinco espaçamentos entre plantas nas linhas de semeadura - EP $(14,4 ; 28,8 ; 43 ; 57,5 ; 72 \mathrm{~cm})$. A unidade experimental foi constituída de quatro linhas de seis metros de comprimento e 0,70 m de espaçamento entre linhas, totalizando 16,8 $\mathrm{m}^{2}$. Para manter a mesma densidade $(60 \mathrm{mil}$ plantas por $\mathrm{ha}^{-1}$ ) em todos os tratamentos, a semeadura foi realizada manualmente, em espaçamento de $0,70 \mathrm{~m}$ entre as linhas. 0 desbaste foi realizado 22 dias após a emergência (DAE), priorizando a distribuição de uma planta em EP14,4, duas plantas agrupadas em EP28,8, três plantas agrupadas em EP43, quatro plantas agrupadas em EP57,5 e cinco plantas agrupadas em EP72.

A semeadura foi realizada em 2 de março de 2016 com semeadora manual (matraca) em sulcos de quatro $\mathrm{cm}$ de profundidade $\mathrm{e}$ adubados no sulco de plantio com $300 \mathrm{~kg} \mathrm{ha}^{-1}$ do formulado 12-15-15, a adubação nitrogenada foi realizada em estádio $V_{3}$ a lanço localizada entre linhas com $180 \mathrm{~kg} \mathrm{ha}^{-1}$ de ureia protegida 45-0000 com base na análise de solo.

O controle das plantas invasoras e insetos praga foram realizados respectivamente com, PRIMÓLEO ${ }^{\circ}$ (Atrazina 40\%) na dose de $6 \mathrm{~L}$ $\mathrm{ha}^{-1}$ em pós-emergência inicial $\left(\mathrm{V}_{3}\right)$ e o controle de insetos praga foi feito com 12 DAE com a aplicação de Engeo Pleno (Tiametoxam 14\%) na dose de $250 \mathrm{~mL}^{-1}$ e MATCH EC ${ }^{\circledR}$ (Lufenurom $5 \%) 250 \mathrm{~mL} \mathrm{ha}{ }^{-1}$. Para controle fúngico foi realizado no pré pendoamento $\left(V_{8}\right)$ com a aplicação de PRIORI XTRA (Azoxistrobina 20\% e Ciproconazol 8\%) $400 \mathrm{~mL} \mathrm{ha}^{-1}$ de forma preventiva juntamente com óleo mineral $(0,5 \%)$. As aplicações de defensivos agrícolas foram realizadas com cilindro de $\mathrm{CO}_{2}$ (bico ADI Jacto 110 O2; barra composta por 6 bicos; gasto de calda equivalente a $200 \mathrm{~L} \mathrm{ha}^{-1}$ ) no período matutino em condições climáticas favoráveis. Para a aplicação dos produtos foram utilizadas garrafas pet de $2 \mathrm{~L}$ como recipiente e dosadores utilizou-se pipetas e provetas.

A colheita das espigas foi realizada manualmente, em trilhadeira estacionária. As variáveis avaliadas foram: produtividade em $\mathrm{Kg}$ $\mathrm{ha}^{-1}$, número de plantas acamadas e quebradas, massa de 1.000 grãos (M1000) em gramas, comprimento da espiga (CE) em $\mathrm{cm}$ e diâmetro de colmo (DC) em milímetros ( $\mathrm{mm}$ ). Os dados de CE e DC foram avaliados aleatoriamente dentro da área útil de cada unidade experimental com trena manual e paquímetro respectivamente. $\mathrm{O}$ número de plantas acamadas foram contabilizadas manualmente e os valores finais foram dispostos em porcentagem (\%).

Os dados coletados foram submetidos à análise de variância pelo teste $F$, com uso do software SISVAR e a comparação de médias foi realizada pelo teste de Tukey $(p \geq 0,05)$ (FERREIRA, 2000). Os resultados também foram submetidos à análise de regressão polinomial para as respostas da variável plantas acamadas quanto a distribuição de plantas na linha de semeadura.

\section{Resultados e discussão}

Conforme a Tabela 1, verificou-se a maior produtividade no híbrido Fórmula de 4.660 $\mathrm{Kg} \mathrm{ha}^{-1}$ no agrupamento de quatro plantas, e, a sua média foi de $4.029 \mathrm{Kg} \mathrm{ha}^{-1}$. O híbrido $2 \mathrm{~A} 401$ expressou a maior produtividade quando houve o agrupamento de cinco plantas com $4.532 \mathrm{Kg} \mathrm{ha}^{-1}$, e, a sua média foi de $3.569 \mathrm{Kg} \mathrm{ha}^{-1}$. Portanto, no híbrido Fórmula verificou-se valores médios acima de $11 \%$ quando comparado ao híbrido 2A401, o que equivale a aproximadamente 8 sacas por ha-1.

Rosa et al. (2016) avaliaram a produtividade de híbridos de milho cultivados em segunda safra, também constataram diferenças entre os dois híbridos (Fórmula e 2A401) na proporção média de $10,2 \%$ com maior produtividade para o híbrido Fórmula. As médias verificadas pelos dois híbridos estudados foram próximas as médias da safra 2016, que conforme Shioga et al. (2016) foram de $4.989 \mathrm{Kg} \mathrm{ha}^{-1}$. Estes autores argumentam que a safra 2016 apresentou menor produtividade média que à safra anterior (2015) que foi de $5.863 \mathrm{Kg} \mathrm{ha}^{-1}$, e justificam que na safra 2016 a cultura ficou exposta às condições climáticas desfavoráveis como baixa precipitação pluvial (Figura 1).

O híbrido Fórmula verificou-se a menor produtividade quando foi semeado com 1 e com 5 plantas agrupadas. No entanto, para o híbrido 2A401 verificou-se o melhor desempenho quando semeadas cinco plantas agrupadas. Estudos com os efeitos da variabilidade na 
distribuição espacial de plantas na linha de semeadura sobre o rendimento de grãos, mostram que a variável diminui com o aumento da desuniformidade espacial entre as plantas na linha de cultivo do milho (SANGOI et al., 2012). Segundo Nielsen (2006) e Horn (2011), quanto maior a desuniformidade na distância espacial entre plantas, maior as perdas na produtividade de milho. Os autores definem que, quanto maior o agrupamento de plantas, maior a desuniformidade e menor a produtividade. No entanto, não foi a resposta do híbrido Fórmula, que manteve sua produtividade independente do número de plantas agrupadas, enquanto o híbrido 2A401 constatou-se o melhor desempenho na mesma situação. Ambos resultados, podem ser devido a características intrínseca ao material vegetal (genética) e/ou características ambientais, o que corrobora trabalhos realizados por Strieder et al. (2007), que demonstraram que o incremento da produtividade do milho dependem do híbrido, das condições ambientais e das práticas de manejo adotadas na cultura.

Sangoi (1990), avaliando a distribuição de plantas na linha de semeadura por dois anos, concluiu que a distribuição uniforme de plantas na linha não resultou em maiores rendimentos de grãos, em comparação a arranjos com duas ou mais plantas agrupadas. Resultados similares foram obtidos por Rizzardi et al. (1994), ao avaliarem diferentes formas de distribuição de plantas na linha, em dois espaçamentos entre linhas. O milho foi capaz de compensar espaços deixados pela desuniformidade de emergência, desde que fosse mantida constante a densidade de plantas.

Tabela 1. Produtividade de grãos $\left(\mathrm{kg} \mathrm{ha}^{-1}\right)$ em dois híbridos semeados em diferentes distribuições de plantas na linha de semeadura em milho de 20 Safra 2016. Londrina, PR.

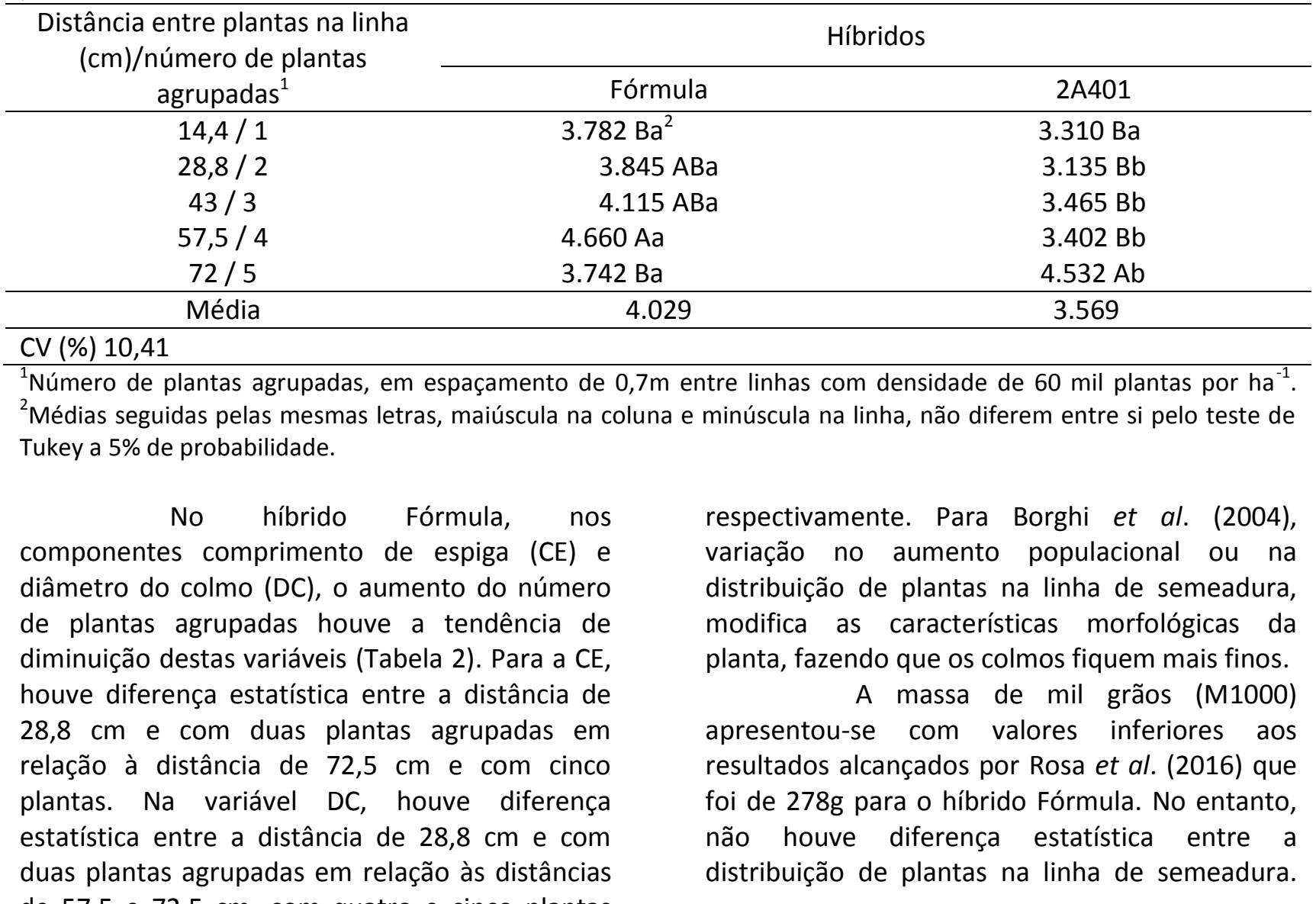


Tabela 2. Variáveis agronômicas do híbrido Fórmula, semeado em diferente distribuição de plantas na linha de semeadura na 20 Safra 2016. Londrina, PR.

\begin{tabular}{cccc}
\hline $\begin{array}{c}\text { Distância entre plantas na linha (cm)/número } \\
\text { de plantas agrupadas }\end{array}$ & $\begin{array}{c}\text { Comprimento de } \\
\text { espiga }(\mathrm{cm})\end{array}$ & $\begin{array}{c}\text { Diâmetro do } \\
\text { colmo }(\mathrm{mm})\end{array}$ & $\begin{array}{c}\text { Massa de mil } \\
\text { grãos (g) }\end{array}$ \\
\hline $14,4 / 1$ & $13,2 \mathrm{ab}$ & $15,5 \mathrm{ab}$ & $181,8 \mathrm{a}$ \\
$28,8 / 2$ & $13,6 \mathrm{a}$ & $17,2 \mathrm{a}$ & $188,4 \mathrm{a}$ \\
$43 / 3$ & $13,7 \mathrm{ab}$ & $14,7 \mathrm{abc}$ & $181,4 \mathrm{a}$ \\
$57,5 / 4$ & $12,1 \mathrm{ab}$ & $12,5 \mathrm{c}$ & $195,5 \mathrm{a}$ \\
$72 / 5$ & $11,4 \mathrm{~b}$ & $13,7 \mathrm{bc}$ & $188,0 \mathrm{a}$ \\
\hline $\mathrm{CV}(\%)$ & 7,31 & 8,35 & 8,00 \\
\hline
\end{tabular}

${ }^{1}$ Número de plantas agrupadas, em espaçamento de $0,7 \mathrm{~m}$ entre linhas com densidade de 60 mil plantas por ha ${ }^{-1}$.

${ }^{2}$ Médias seguidas pelas mesmas letras na coluna não diferem entre si a 5\% de probabilidade - Tukey.

No híbrido 2A401, houveram respostas distintas nos componentes comprimento de espiga (CE) e diâmetro do colmo (DC), com o aumento do número de plantas agrupadas (Tabela 2). Houve diferença com maior CE quando houve uma e três plantas agrupadas, diferindo somente da distribuição com quatro plantas agrupadas. No caso da DC não houve diferença entre a distribuição de plantas na linha de semeadura.

A massa de mil grãos (M1000) apresentou-se com valores inferiores aos resultados alcançados por Rosa et al. (2016) que foi de 284g para o híbrido 2A401, e assim como o híbrido Fórmula, não houve diferença entre a distribuição de plantas na linha de semeadura.

Tabela 3. Variáveis agronômicas do híbrido 2A401, semeado em diferente distribuição de plantas na linha de semeadura na 2o Safra 2016. Londrina, PR.

\begin{tabular}{cccc}
\hline $\begin{array}{c}\text { Distância entre plantas na linha }(\mathrm{cm}) / \text { número } \\
\text { de plantas agrupadas }\end{array}$ & $\begin{array}{c}\text { Comprimento de } \\
\text { espiga }(\mathrm{cm})\end{array}$ & $\begin{array}{c}\text { Diâmetro do } \\
\text { colmo }(\mathrm{mm})\end{array}$ & $\begin{array}{c}\text { Massa de mil } \\
\text { grãos (g) }\end{array}$ \\
\hline $14,4 / 1$ & 12,7 a & 14,7 a & 212,6 a \\
$28,8 / 2$ & 12,5 ab & 13,5 a & 196,9 a \\
$43 / 3$ & 13,1 a & 15,7 a & 203,4 a \\
$57,5 / 4$ & 10,7 b & 15,5 a & 229,3 a \\
$72 / 5$ & 12,2 ab & 14,5 a & 214,6 a \\
\hline CV (\%) & 7,31 & 8,35 & 8,00 \\
\hline
\end{tabular}

${ }^{1}$ Número de plantas agrupadas, em espaçamento de $0,7 \mathrm{~m}$ entre linhas com densidade de 60 mil plantas por ha ${ }^{-1}$.

${ }^{2}$ Médias seguidas pelas mesmas letras na coluna não diferem entre si a $5 \%$ de probabilidade - Tukey.

Quando houve maior número de plantas agrupadas também houve uma maior porcentagem de plantas acamadas (Figura 2A), nos dois híbridos estudados. No híbrido Fórmula constatou-se valores baixos na distância $14,4 \mathrm{~cm}$ com uma planta (4\%), e, a maior porcentagem de acamados foi na distância $72 \mathrm{~cm}$ com cinco plantas acamadas (28\%). No caso do híbrido 2A401 houve pouca variação entre as quatro primeiras distâncias, no entanto, a maior porcentagem de acamada foi constatada na distância $72 \mathrm{~cm}$ com cinco plantas (31\%). As maiores médias de plantas acamadas foram apresentadas pelo híbrido 2A401 em todas as distâncias entre plantas na linha de semeadura, sendo a maior quando não houve agrupamento de plantas.

As maiores médias de plantas quebradas ocorreram quando houve maior número de plantas agrupadas (Figura 2B), nos dois híbridos estudados. O híbrido Fórmula constatou-se resposta linear da variável plantas quebradas quando houve o aumento de plantas agrupadas, enquanto o híbrido 2A401 apresentou resposta exponencial. Ferreira et al. (2009) também encontraram resultados semelhantes, com interação para porcentagem de plantas acamadas e não significativo para a porcentagem de plantas quebradas. 
Segundo Gomes et al. (2010), o quebramento e o acamamento são fenômenos complexos, e sua expressão depende de fatores genéticos, inter-relacionados com fatores do clima, do solo, das práticas culturais adotadas e de danos causados por pragas e doenças. Entre os principais agentes que promovem acamamento e quebramento destacam-se a chuva e o vento, que na safra 2016, em consequência de frentes frias frequentes a partir de maio, verificaram-se fortes vendavais (SHIOGA et al., 2016) o favoreceu o aumento nas porcentagens destas duas variáveis.

Figura 2. Porcentagem de plantas acamadas (A) e quebradas (B) em dois híbridos de milho semeados em diferente distribuição de plantas na linha de semeadura na 2ㅇ Safra 2016. Londrina, PR.

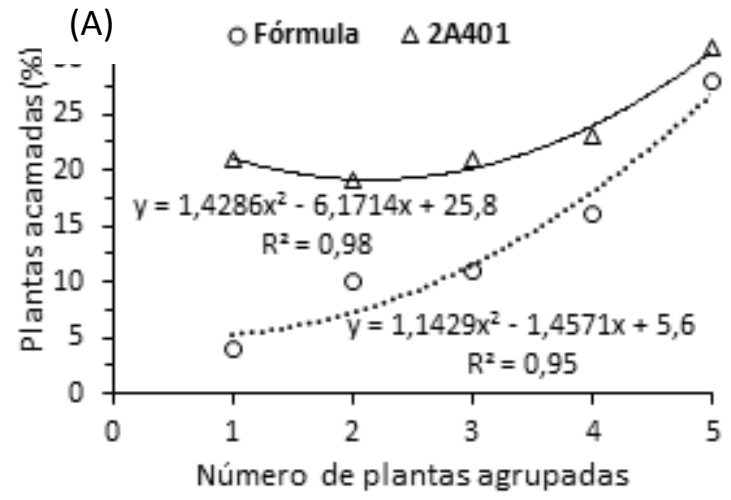

No híbrido Fórmula constatou-se maior produtividade de grãos em comparação ao 2A401 (Tabela 1) e também menor número de plantas acamadas (Figura 2A). A densidade populacional ocorrida pelo agrupamento das plantas, interferiu na massa individual das plantas, obtendo-se um decréscimo de massa seca individual, nomeadamente do colmo, como resultado da competição entre elas pelos recursos do meio. Isto ocasionou uma tendência das plantas ficarem suscetíveis ao acamamento (GROSS et al., 2006), por consequência, refletindo no rendimento da cultura.

As respostas ocorridas no presente trabalho podem ser em decorrência das adversidades climáticas ocorridas na safra 2016, com o registro de estresses hídricos, baixas temperaturas e baixa luminosidade que prejudicaram o desenvolvimento das plantas de milho (Figura 1). Segundo Shioga et al. (2016) a condição climática no período de cultivo do milho segunda safra (2016) foi caracterizada pela transição do fenômeno El Niño para a neutralidade, com a predominância de atuação do fenômeno El Niño no início da safra. Em abril, houve a ocorrência de altas temperaturas, que associadas à baixa precipitação prejudicaram as lavouras de milho. Temperaturas baixas a partir do mês de maio e a incidência de geadas em

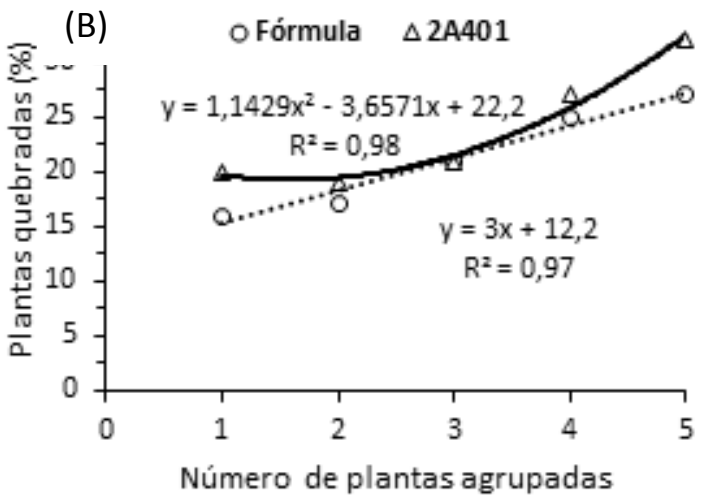

meados de junho foram outros fenômenos climáticos que afetaram negativamente as lavouras de milho. Essas variações climáticas anormais, muito aquém dos padrões considerados bons para o desenvolvimento da cultura, provocam condições altamente estressantes para a cultura, o que predispõe as plantas às doenças, o que contribui ainda mais para as baixas produtividades.

\section{Conclusão}

Existe variabilidade genética para o rendimento de grãos quanto a distribuição de plantas na linha de semeadura.

O híbrido Fórmula foi capaz de compensar os espaços deixados pela desuniformidade na linha de semeadura.

\section{Referências}

ANDRADE, F. H.; SADRAS, V. O. Bases para el manejo del maiz, el girassol e la soja. Buenos Aires: Médica Panamericana, 2003. 443 p.

BORGHI, E.; MELLO, L. M. M.; CRUSCIOL, C. A. C. Adubação por área e por planta, densidade populacional e desenvolvimento do milho em função do sistema de manejo do solo. Acta Scientiarum. Agronomy, v. 26, n. 3, p. 337-345, 
2004.

https://doi.org/10.4025/actasciagron.v26i3.1840

FERREIRA, J. M.; MOREIRA, R. M. P.; HIDALGO, J. A. F. Capacidade combinatória e heterose em populações de milho crioulo. Ciência Rural, v.39, p.332-339, 2000. https://doi.org/10.1590/S0103$\underline{84782008005000058}$

GOMES, L. S.; BRANDÃO, A. M.; BRITO, C. H.; MORAES, D. F.; LOPES, M. T. G. Resistência ao acamamento de plantas e ao quebramento do colmo em milho tropical. Pesquisa agropecuária brasileira, v.45, n.2, p.140-145, fev. 2010. https://doi.org/10.1590/S0100-

204X2010000200004

GROSS, M. R.; PINHO, R. G.; BRITO, A. H. Adubação nitrogenada, densidade de semeadura e espaçamento entre fileiras na cultura do milho em sistema de plantio direto. Ciência e Agrotecnologia, v.30, p.387-393, 2006. https://doi.org/10.1590/S1413-

$\underline{70542006000300001}$

HORN, D. Qualidade de plantio: uma nova abordagem. Boletim Informativo da Pioneer, v. 3, p. 17-19, 2011.

JUNIOR, P. A. V. et al. População de plantas e alguns atributos do solo relacionados ao rendimento de grãos de milho. Acta Scientiarum, v.28, n.4, p.483-492, 2008. DOI: 10.4025 /actasciagron.

NIELSEN, R. L. Effect of plant spacing variability on corn grain yield. Purdue University Department of Agronomy-Corny News Network, 2006.

RIZZARDI, M. A.; BOLLER, W.; DALLOGLIO, R. Distribuição de plantas de milho, na linha de semeadura e seus efeitos nos componentes de produção. Pesquisa Agropecuária Brasileira, v. 29, n. 8, p. 1231-1236, 1994.

ROSA, R. P.; PITTELKOW, F. K.; PASQUALLI, R. M. Avaliação de híbridos de milho na segunda safra em dois níveis de tecnologia em Lucas do Rio Verde - MT. 2016. Disponível em: http://www.fundacaorioverde.com.br/publicacoe s/143. Aceso em: 17 abr. 2019.

SANGOI, L. Arranjo de plantas e características agronômicas de genótipos de milho em dois níveis de fertilidade. Pesquisa Agropecuária Brasileira, Brasília, v.25, n.7, p.12-14, 1990.

SANGOI, L.; SCHMITT, A.; VIEIRA, J.; PICOLI JR, G. J.; SOUZA, C. A.; CASA, R. T.; SCHENATTO, D. E.; GIORDANI, W.; BONIATTI, C. M.; MACHADO, G. C.; HORN, D. Variabilidade na distribuição especial de plantas na linha e no rendimento de grãos de milho. Revista Brasileira de Milho e Sorgo, v.11, p.268-277, 2012. https://doi.org/10.18512/19806477/rbms.v11n3p268-277

SANGOI, L.; SCHWEITZER, C.; SILVA, P. R. F.; SCHMITT, A.; Vargas, V. P.; CASA, R. T; SOUZA, C. A. Perfilhamento, área foliar e produtividade do milho sob diferentes arranjos espaciais. Pesquisa Agropecuária Brasileira, Brasília, DF, v. 46, n.5, p. 609-616, 2011. https://doi.org/10.1590/S0100$\underline{204 \times 2011000600006}$

SANGOI, L.; SILVA, P. R. F.; ARGENTA, G. Estratégias de manejo do arranjo de plantas para aumentar o rendimento de grãos do milho. Lages: Graphel, 2010. 64 p.

SANTOS, H. G.; JACOMINE, P. K. T.; ANJOS, L. H. C.; OLIVEIRA, V. A.; LUMBRERAS, J. F.; COELHO, M. R.; ALMEIDA, J. A.; CUNHA, T. J. F.; OLIVEIRA, J. B. Sistema brasileiro de classificação de solos. 3. ed. Brasília: Embrapa, 2013.

SHIOGA, P. S.; GERAGE, A. C.; ARAÚJO, P. M.; BIANCO, R.; BARROS, A. S. R.; CUSTÓDIO, A. A. P. Avaliação estadual de cultivares de milho segunda safra 2016. 1. ed. Londrina: IAPAR, 2016. 58p. (IAPAR Boletim Técnico; 88).

STRIEDER, M. L.; SILVA, P. R. F.; ARGENTA, G.; RAMBO, L.; SANGOI, L.; SILVA, A. A.; ENDRIGO, P. C. A resposta do milho irrigado ao espaçamento entrelinhas depende do híbrido e da densidade de plantas. Ciência Rural, Santa Maria, v. 37, n. 3, p. 634-642, 2007. https://doi.org/10.1590/S0103$\underline{84782007000300006}$ 